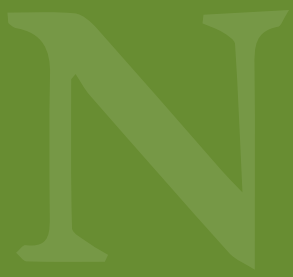

SEccion: Problemas espaciales contemporaneos
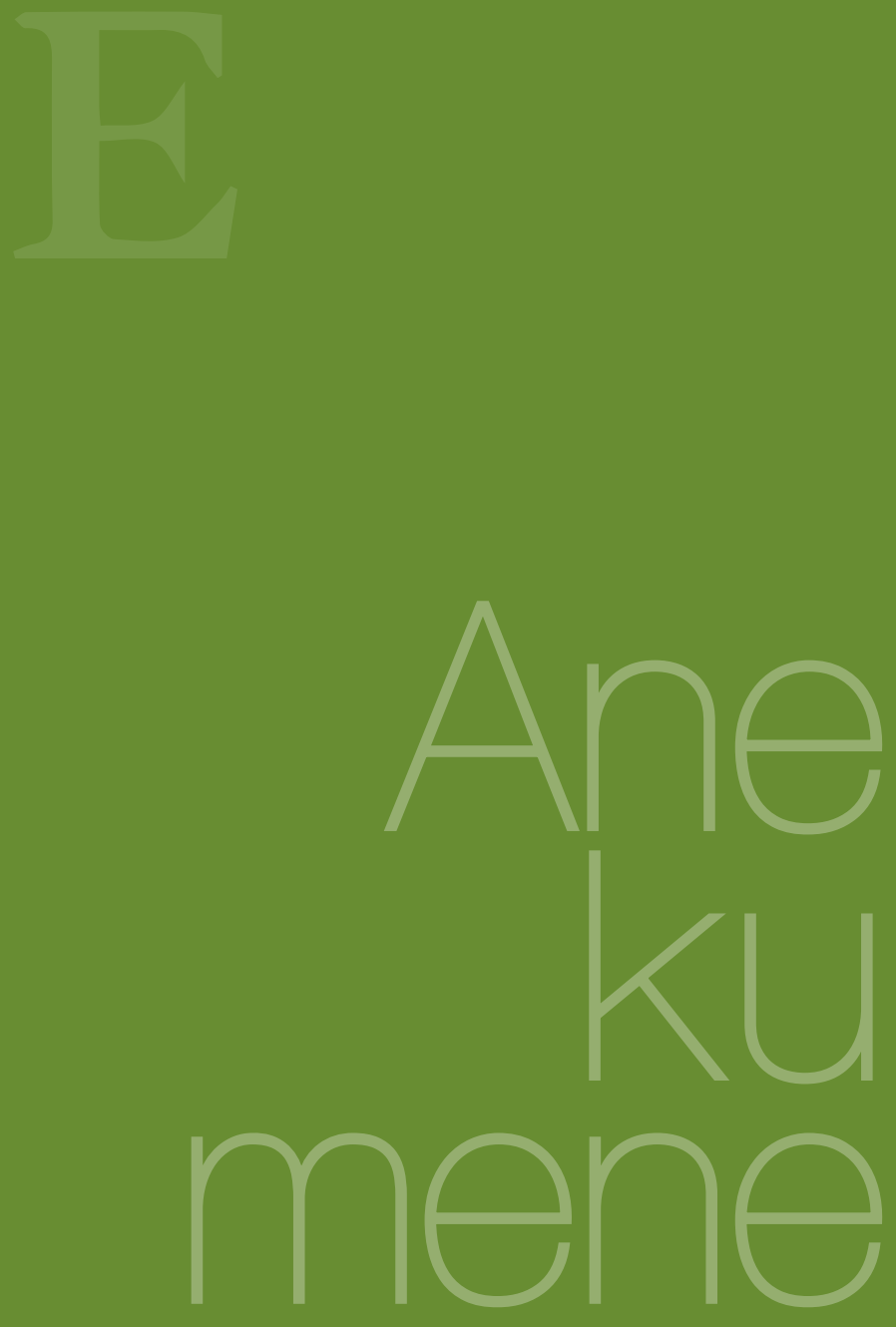


\section{El espacio público bajo el contexto de las urbanizaciones: críticas y oportunidades}

\section{Public Space under the Context of Urbanizations: Criticism and Opportunities}

\section{O espaço público sob o contexto das urbanizações: críticas e oportunidades}

Cristian Yesid Gómez Mora*

\begin{abstract}
Resumen
El espacio público, entendido como escenario de interacción y participación humana, deviene como elemento sustancial del entramado urbano que fomenta el potencial comunicativo de la ciudad. Lo público advierte la necesidad de reconocer y encontrarse con el otro y, además, implica aceptar la diferencia en pro de la preservación de escenarios heterogéneos. Por lo tanto, el presente artículo busca dilucidar aquellas características fundamentales del espacio público, sus principales dimensiones y puntos trascendentales; se preocupa por aclarar su condición protagónica dentro de la ciudad y por evidenciar su importancia en lugares estratégicos, como las urbanizaciones o los conjuntos residenciales.
\end{abstract}

\section{Palabras clave}

espacio público; urbanizaciones; ciudad. 
El espacio público bajo el contexto de las urbanizaciones: críticas y oportunidades Cristian Yesid Gómez Mora

\section{Abstract}

Public space, understood as a scenario of human interaction and participation, becomes a substantial element of the urban fabric that fosters the communicative potential of the city. The public domain advises the need to recognize and meet with the other, and it involves the acceptance of that which is different in favor of supporting heterogeneous scenarios. As a result, this paper aims to elucidate the fundamental characteristics of public space, as well as its main dimensions and transcendental points; it seeks to clarify its protagonism in the city and to demonstrate its importance in strategic places, such as urbanizations or residential complexes.

\section{Resumo}

O espaço público, entendido como cenário de interação e participação humana, vira elemento substancial do tecido urbano que fomenta o potencial comunicativo da cidade. 0 público advierte a necessidade de reconhecer e se encontrar com o outro e, além disso, aceitar a diferença visando a preservação de cenários heterogêneos. Por tanto, o presente artigo procura determinar aquelas características fundamentais do espaço público, suas principais dimensões e pontos transcendentais. Além do mais, visa aclarar sua condição protagónica dentro da cidade e evidenciar sua importância em lugares estratégicos, como as urbanizações ou condomínios residenciais.

\section{Keywords}

public space; housing developments; city.

\section{Palavras-chave}

espaço público; urbanizações; cidade. 


\section{Lo público como escenario de interacción}

Las diferentes dimensiones del espacio público, relacionadas con sus características físicas y sociales, han potenciado las reflexiones sobre este y categorizado el conjunto de dinámicas que le han sido propias a lo largo de la historia. Para algunos urbanistas y arquitectos interesados en la planificación de la ciudad, la formalización de escenarios públicos suscita, como actividad principal, la creación y distribución de equipamientos; sin embargo, otros teóricos han privilegiado las vinculaciones humanas con lo espacial, rescatando la preponderancia del hombre público por encima de todo. Isaac Joseph (1999) sostiene que las amplitudes del paisaje urbano, consolidado a partir de un holgado contenido público, imprimen en los individuos un deber de exposición y una permanencia continua con el extraño. Ello entrevé que el escenario de la acción y, por ende, el ejercicio de disputa se inscriben en las ambientaciones propias de la cosa pública, donde emerge la heterogeneidad y la ambivalencia como punto vertebral.

El presente artículo acoge la categoría de espacio público como eje de partida y asume su conceptualización a la luz de posturas teóricas desarrolladas por autores como Jordi Borja (2003), Richard Sennett (1978), Hannah Arendt (2003) y Manuel Delgado (1999). Para ellos el escenario de lo público afianza las propiedades humanas de la acción, la participación, la interacción e incluso la conflictividad, reafirmando con ello las capacidades comunicativas que se generan dentro de él. Para Delgado (1999), lo público facilita el despliegue de la alteridad generalizada, cosa que el autor explica a través de una analogía vinculada con el juego. Los diferentes participantes y protagonistas (de la escena pública) consolidan su actuación y teatralidad en un conjunto de reglas que florecen como propias de la condición humana -hablar, caminar, observar-; no obstante, su desconfianza frente al otro desconocido permite el auge de sistemas de protección que impiden el reconocimiento de sus verdaderas personalidades. En consecuencia, lo anterior constata que la movilidad del espacio público, recreada en las particularidades culturales y sociales de la población, se presenta como garantía de intervención, pero asimismo de prevención de un escenario tan alterno como este, dando paso a un hombre de cualidades públicas que "retoma una invisibilidad relativa, consistente en ser visto y no visto, ser tenido en cuenta pero sin dejar de ocultar su verdadero rostro" (Delgado, 1999, p. 17).

En el trabajo presentado por Delgado (1999), dichas peculiaridades del espacio público son las que lo hacen interesante de estudiary analizar; su camuflaje, alteridad, heterogeneidad y transformación permiten cultivar un campo académico sobre su corporeidad humana y arquitectónica. Como lo afirma Borja (2003), sus facetas físicas, simbólicas y políticas se concentran en las cambiantes direcciones que puede conquistar. Para este autor, el espacio público se manifiesta precisamente en aquel escenario reconocedor del conflicto, la participación y la integración: la ciudad. En ella las propiedades del espacio colectivo se hacen realidad, se conjugan las posiciones urbanísticas y sociales, y se afianza la hibridad como posibilidad de encuentro. Por esta razón, Borja (2003) sostiene que el espacio público es propiamente la ciudad, que a partir de él la calidad de esta se define y que en su suelo es donde la sociedad realmente se hace palmaria, acompañada de aquel hombre invisible que rescató Delgado (1999) como figura de publicidad.

La ciudad es espacio público, recalca Borja (2003), una concentración de puntos de encuentro y una urdimbre de espacios colectivos. Sin embargo, ¿qué es realmente la ciudad?, ¿qué es lo que la hace tan importante de analizar? Tal y como lo entendió Jane Jacobs (2011) en Muertey vida de las grandes ciudades, la ciudad es el escenario propio del extraño, donde se preserva la divergencia y se prima la relación armónica entre equipamientos y ciudadanos. Una buena ciudad debe privilegiar los vínculos humanos que se tejen en su entorno y, aún más, garantizar la seguridad de aquellos personajes que se involucran con desconocidos. Jacobs (2011) reconocía perfectamente las amplias capacidades de la ciudad para afianzar un entramado de alteraciones y cambios que permitieran superar la inseguridad como principal inconveniente que la aqueja; sus constantes transformaciones en pro de la monotonía espacial y el olvido de criterios trascendentales, como la fluidez y la continuidad, han condenado al componente urbano a un desalojo de las capacidades humanas que lo conforman. Ante ello es claro que la libertad y la seguridad, proclamadas como elementos indispensables por Jacobs (2011), se formalizan como atributos únicos de una ciudad pensada, donde se considera que sus dinámicas dan viabilidad a los intercambios y las ambivalencias que la hacen tan peculiar.

Ahora bien, bajo un contexto en el que se reclama celeridad, es pernicioso desplegar acciones individuales y estáticas; por el contrario, se deben rescatar las capacidades que alimentan la circulación del contacto y la expresión. Jacobs (2011) es precisa en reclamar la calle como elemento estructural de la trama urbana, la cual acoge aquellas características que Borja (2003) relacionó con la diversidad de usos. Su protagonismo debe sobresalir, al igual que la participación constante de usuarios y la delimitación clara entre lo público y lo privado. Para la autora el espacio público es vertebral en tanto aglutina la confianza como fluido principal de sus arterias, a partir de ella la identidad pública entre comunidades emerge y se formalizan organizaciones comunales que amparan vías de participación de firmeza estable.

Al igual que Jacobs (2011), Isaac Joseph (1999) vislumbra la exposición de los extraños al interior del paisaje urbano y evidencia que en él se propicia la germinación de un contenido público. El encuentro se proclama como agenda propia del espacio colectivo que permite la interacción humana a partir de esa heterogeneidad alimentada por el desconocido. Joseph (1999) sostiene que formalizar el escenario de la ciudad como teatro de la acción, analogía que asume igualmente Sennett (1978), invita a valorizar el dominio de lo público y a transformar su contenido 
en pro de la disputa y la alteración. Así, asegurar que el espacio público es el terreno del conflicto y la conflagración, a la vez que representa la caducidad de la individualidad, es la apuesta de Joseph (1999), en tanto la sociabilidad y la comunicación se asumen como potenciales caminos de intersubjetividad. Para el autor este espacio es un dispositivo de dramatización que moviliza todo un conjunto de equipamientos, actividades y pensamientos; en él se construye una visibilidad mutua y se permite continuamente el desplazamiento.

Isaac Joseph (1999) conduce a una definición de espacio público que se vincula con el concepto de acción, donde se difunde una profunda cooperación y se despliega la adaptación promulgada por el contacto. Dentro de él se establece un orden bifurcado que analiza las amplitudes que se potencian con esta: el de las visibilidades, que atiende la pluralidad de usos y perspectivas, y el de las interacciones, que reúne el conjunto de los encuentros efectuados. Los anteriores permiten comprender que para el autor el espacio público no asciende únicamente como producto institucional, sino que, por el contrario, cobija el atuendo de las prácticas de usuarios, las decisiones relacionadas con el espacio, las rutinas cotidianas y los comportamientos particulares, cosa que preocupa profundamente en la antropología de lo urbano proclamada por Delgado (1999).

Para el antropólogo español, las agitaciones humanas presentes al interior del espacio público, donde revolotea el contacto que fue tan importante en Jacobs (2011), es lo que inquieta a una antropología resguardada en la ciudad. Quizás esta es la principal apuesta de Delgado (1999) al afirmar que lo público es el campo de la ambivalencia; no obstante, es claro al validar las divergencias que se encuentran vigentes entre la urbanidad y la ciudad. Esta última, para el autor, se sitúa como asentamiento de construcciones estables donde es posible o no la permanencia de la urbanidad. En ella se encuadra la movilidad, la agitación, los desequilibrios y los resultados de un conjunto de protagonistas presentes en un mundo habitado por desconocidos. Así, dicha afirmación contrasta con la conceptualización presentada por Jacobs (2011), en la que se obvia, o más bien se pausa, la formalidad física como elemento primordial. Las declaraciones de Delgado (1999) continúan cuando precisa la definición concreta de ciudad, calificándola de composición espacial definida por la densidad poblacional y el asentamiento de un amplio número de construcciones, donde, a pesar de ello, germina un estilo de vida caracterizado por lo fortuito.

Contrario a Delgado (1999), Jacobs (2011) no identifica una separación latente entre la ciudad y la conducta humana que se teje dentro de ella. Más bien, su definición se asemeja a lo que este autor denomina urbano, es decir, el enjambre del extraño, lo aleatorio y lo impredecible. Dichas aserciones se evidencian a través de las páginas de El animal público, editado por primera vez en 1999, pero años después, con la aparición de El espacio público como ideología (2011), la ciudad supera su primera definición y se concibe como estructura de calidades socialmente esta- blecidas; así, ya no es solo la suma de cantidades o estadísticas sino un campo de significaciones que prefigura la experiencia de lo urbano. Lo anterior refleja que el espacio público aguarda la coexistencia de una sociedad heterogénea, donde se establece el ámbito para el libre acuerdo y se asume una connotación política que devela la relación con los demás. Para Delgado (2011) lo público aventaja las diferentes explicaciones que urbanistas y teóricos han aplicado al interior de sus disciplinas; concebirlo como simple lugar abierto o como llana formalidad de la ciudad diluye la verdadera naturaleza que le atribuye el autor a su corporeidad diversa: la igualdad.

Dentro del espacio público es posible enaltecer la experiencia democrática que muchas ciudades del mundo han intentado proclamar; en él es factible palmar la divergencia del accionar humano y, como lo rescata Delgado (2011), disolver momentáneamente las relaciones clásicas de dominación. Justamente el ambiente de lo público florece como morada democrática en las posturas teóricas presentadas en este artículo, que, a la vez que resumen categorías preponderantes como ciudad y participación, se inquietan por el ciudadano como principal protagonista. En el caso de Borja (2003), el espacio colectivo es propiamente el escenario de la ciudadanía, amparada en la mixtura funcional y la participación de condición diversa. Dentro de ella, ya considerada producto de lo público, el espacio se admite como elemento trascendental donde germinan iniciativas ciudadanas y ascienden, así mismo, las tensiones relacionadas con la crisis de la ciudad. Por tanto, más allá de su formulación jurídica y delimitación perimetral, su uso es lo que realmente resulta sustancial.

Para Jordi Borja (2003) el uso colectivo, la multifuncionalidad y la accesibilidad juegan como volantes en el partido de la calidad pública. Precisamente, esta es evaluada a partir de la intensidad y la fluidez de las relaciones facilitadas, la mezcla generada entre diferentes grupos ciudadanos y la promoción de interacciones igualitarias. Sin embargo, es evidente que los problemas de la ciudad actual han escalado en circuitos de disolución, fragmentación y privatización. Para Borja (2003), estos elementos representan la trayectoria de una vida desligada y una acción convertida en monotonía; a partir de ellos se invita a formalizar una ciudad con terminaciones públicas, ambivalentes y conflictivas, garantizando un espacio que divulgue movilidad y permita la invitación de hacer ciudad sobre la ciudad.

La vida pública se ha transformado considerablemente desde el auge y advenimiento de la modernidad, afirma Sennett (1978). Con ella las relaciones humanas se fundamentaron en patrones sociales de obligación y ascendieron a dinámicas frívolas, formales e, inclusive, falsas. Así, aquel extraño protagonista de la ciudad de Jacobs (2011) deviene en Sennett (1978) como razón problémica, o, más bien, considerando las ambigüedades de la vida contemporánea, como amenaza que impide el disfrute y goce de la interacción. Este personaje que aparece como vertebral en las afirmaciones teóricas de Borja (2003) y Delgado (1999), 
presume su disolución en medio de las argumentaciones que aseveran el declive del hombre público. Con la modernidad las acciones se desvanecieron en apropiaciones privadas de lo común, asumiendo en consideración individual aquello que otrora se afrontaba al diálogo y la exposición colectiva. Por consiguiente, el autor revela los graves problemas públicos que la sociedad ha concebido con el correr del tiempo, acumulados en transformaciones culturales y deterioros de la ciudadanía que Borja (2003) proclamó como hija de la publicidad.

Tanto la pérdida de interés por los asuntos públicos como la atención que se le otorga cuando se estima que se trata de cuestiones personales se reflejan en las reflexiones de Sennett (1978) como problemáticas vertebrales del asunto; la verdadera esencia del espacio público se ha perdido y se levanta ahora un monumento en decoro al desarraigo y la individualidad latente. Como Sennett (1978), Borja (2003) también sostiene que las particularidades públicas, dilucidadas en la alteridad de sus dinámicas, se ven atareadas por cuestiones malsanas que socaban sus potenciales expositivos tan provechosos para la sociedad. Entre ellos, el más crítico y frecuente, hallado en los tejidos de la ciudad, se relaciona con la privatización propia de modelos económicos que se abastecen de capitales particulares y procuran el derribo democrático de lo público. No obstante, lo importante es comprender que ante aquellas dificultades, engendradas y apropiadas por la vida, se presentan alternativas que suscitan pluralidad de propuestas manejadas por autores que, como Borja (2003), se han interesado por la humanización de la ciudad.

Para el geógrafo español, la regeneración, la reconversión y la producción exnovo representan la superación del olvido y la recomposición del espacio; todas ellas simbolizan desafíos que la sociedad apropia con el tiempo y la ciudad se encarga de asumir en términos culturales y urbanísticos. Por su parte, la regeneración implica la apertura de escenarios cerrados y la mejora de algunos rezagados, como sucede con la calle. La reconversión atiende el proyecto de convertir en espacio público áreas potenciales y obsoletas -industrias clausuradas, puertos abandonados, cuarteles en desuso-, mientras la producción exnovo concibe la ejecución de planeaciones desde la línea de partida. Así, las condiciones propuestas por Borja (2003) emanan de un análisis geográfico y social que apuesta por un uso del espacio público en términos de diversidad, tal y como lo promovió Jacobs (2011) en algún momento de su obra. Como se mencionó anteriormente, esta autora es clara en evidenciar que la ciudad, presente como escenario del extraño, asciende en medio de la heterogeneidad de gustos, comportamientos, y tratamiento económico y cultural. Por ello, a fin de generar una diversidad en las calles, promueve cuatro condiciones interesantes de aplicar: la promoción de accesibilidad por parte de los distritos urbanos a diferentes equipamientos y multiplicidad de horarios; el desarrollo de manzanas pequeñas y calles abundantes; la mezcla de edificios en pro de la preservación de variedad; y la concentración humana suficientemente densa. Estas cuestiones se anclan a un contenido reflexivo sobre la ciudad y a una planificación urbana que apunta a la animación de las calles, la continuidad arquitectónica y la diversidad de los lugares públicos, sujetados al camino de la acción que Arendt (2003) presentó como pieza imprescindible.

Como muchos otros teóricos, Hannah Arendt (2003) se ha inquietado precisamente por las variables de la actividad humana en el terreno de la publicidad. En ella la acción se fundamenta en el encuentro con los demás y se hace importante en el punto en que genera cohesión, pero también conflictividad. Para Arendt (2003), la esfera pública, comprendida a partir de la fuerte tradición griega, se formaliza como producto de la acción y el discurso que validan el corpus de la condición humana. Frente a esta, contraria y claramente diferente, se halla la vinculada con lo privado, que se enlaza con el círculo familiar identificado como antítesis de la espacialidad pública desde la Antigüedad. Así, determinando la separación entre las dos esfericidades, impulsadas como parte de la vida en el mundo griego, Arendt (2003) afirma que aquella división característica de la ciudad-Estado se difuminó con la llegada de la modernidad, a la vez que terminó con el fundamento libertario de la polis y la clásica necesidad imperante en la familia.

Contrario a Arendt (2003), Habermas (1981) sostiene que con la formalización de la sociedad burguesa y, por tanto, con la resignificación de la opinión pública, se estableció una separación concreta entre las facultades privadas y públicas de la vida. Como lo afirma el autor, en el contexto propio de la Edad Media la presencia de una unidad confusa entre las dos esfericidades fue ampliamente evidente; la publicidad cortesana mantuvo las condiciones de la representación pública de dominio y obstruyó la deliberación aclamada por la sociedad griega. No obstante, el advenimiento del capitalismo financiero reorganizó las interacciones humanas de la época y permitió que se reordenaran las relaciones dominantes tan trascendentes para la aristocracia. El Estado moderno precisó la delimitación entre los bienes domésticos y los bienes estatales, y permitió la concepción de lo colectivo como entidad aparte de la individualidad.

Por tanto, Habermas (1981) nos recuerda que bajo este contexto histórico público resulta análogo a estatal y, por ende, despierta dentro de él las actividades de una sociedad aburguesada. A este punto la publicidad burguesa representa el nivel en el que las personas privadas se reúnen en calidad de público, impulsadas por aquellas instituciones -el café, los salones, etc.- aclaradoras de la conversación en pro de intereses colectivos. Sin embargo, como lo recalca Arendt (2003), la sociedad moderna también aclimató la desnudez de la vida pública, incitando, por un lado, el ascenso de lo doméstico a los asuntos generales y, por otro, la decadencia de la característica libertad pública. Ahora, en un contexto donde la simple formalidad imperaba, el desarrollo de un conformismo era inminente; la sociedad aguardó el olvido de lo público y se dio el lujo de acatar actividades de supervivencia - el trabajo- en el escenario de la publicidad, obviando la relevancia de la acción comunicativa habermasiana y la noción arendtiana de poder. 
En consecuencia, el espacio público sintetiza los matices de la intersubjetividad humana que recuerda las amplitudes de la discursividad, pero también de la liminalidad, que Delgado (2011) presentó como sustancial de la espacialidad pública. Los ambientes colectivos están recreados en medio de la indefinición y se convierten constantemente en lugares de paso; por ello, su característica principal supone la multiplicidad de usos, flujos y comportamientos, y a partir de ellos, impera el anonimato y la neutralidad de desigualdades como hilo conductor de la ciudad. Como lo afirmó Habermas (1989), el espacio público es el ámbito de la vida social donde se forma la opinión pública, y en él confluyen debates colectivos interesados por asuntos habituales que se acogen sin ningún tipo de coacción. Así, es grato mencionar que las diferentes perspectivas teóricas asumidas en el presente artículo reclaman por un espacio público de calidad diversa, donde la alteridad, la comunicación y la dispersión son todas protagonistas, aseverando con ello las reflexiones de Arendt (2003) acerca de la publicidad y la verdadera condición mundana: "la realidad de la esfera pública radica en la simultanea presencia de innumerables perspectivas y aspectos en los que se presente el mundo común y para el que no cabe inventar medida o denominador común" (p. 66).

\section{Espacio público y conjuntos residenciales}

El espacio público presente en conjuntos residenciales o urbanizaciones y complejos de vivienda ha sido analizado desde diferentes puntos de vista, concebido como escenario privatizado o espacio comunitario. Por un lado, Blakely y Snyder (1999) afirman que los brotes segregativos de las gated communities en Estados Unidos y el resto del mundo invaden los componentes sociales y culturales de la ciudad; por otro, Germán Samper (1997) le apuesta a un modelo de vivienda donde lo público consolida la oportunidad de interactuar y convivir con otros sin ningún tipo de restricción. Así, el espacio público es visto, de un lado, como elemento susceptible de privatización, atado a las dinámicas de las urbanizadoras, pero, por otro, se vislumbra como potencial de apropiación que permite el desarrollo eficaz de complejos residenciales. Veamos pues ambas posiciones.

En el transcurso de su trabajo, Blakely y Snyder (1999) evidencian el esfuerzo de las residencias cerradas por sustituir elementos comunitarios por aquellos de carácter privativo. Aclaran que sus dinámicas amparan la exclusividad como punto de partida y reflejan que en ellas se despliegan un conjunto de tensiones que sintetizan su ambivalencia: privatización-bienestar público; controles de vecinos-el extraño como compañero; seguridad y protección-responsabilidad cívica. Como también lo sostiene Mike Davis (2003), las construcciones residenciales de características cerradas se subsumen en un abismo de desunión que altera las continuidades de la ciudad. En los análisis presentados en Ciudad de cuarzo, Davis (2003) propone un cúmulo de consecuencias que se cosechan de las implementaciones urbanísticas llevadas a cabo en metrópolis como Los Ángeles. La generación de demandas paranoicas por la amplia oferta de seguridad que priorizan los conjuntos amurallados se formaliza como resultado considerable del auge de las urbanizaciones; no obstante, evidenciando las transformaciones del espacio y las interacciones humanas, Davis (2003) señala que la destrucción del espacio público accesible asciende como consecuencia principal de aquel modelo de vivienda.

Para Blakely y Snyder (1999), las gated communities son producto del avance de promotores urbanísticos, la competencia entre ellos y la amplia demanda de sus productos. Además, se catalogan como una nueva forma de discriminación moderna y se determinan como estructuras típicas de exclusividad. Blakely y Snyder (1999) son claros al vislumbrar la oferta creciente de seguridad que estos modelos de vivienda asumen en las periferias de las ciudades; la protección se encuadra como principal característica de las urbanizaciones cerradas y la colocación de barreras como elemento primordial de dicha promoción.

Las comunidades de características cerradas afianzan un conjunto de diferencias que se adhieren a una tipología acentuadora del estilo, la condición y las relaciones socioeconómicas. En la tabla 1, tomada de un documento de Blakely y Snyder (1997), se evidencia la preponderancia de la seguridad, el status y el patrón servicios como conceptos indispensables de las agrupaciones residenciales de Estados Unidos; no obstante, es manifiesto que las vinculaciones y las clasificaciones situadas por ambos autores se acoplan perfectamente a las dinámicas latinoamericanas e, incluso, colombianas. En el trabajo desarrollado por Maristella Svampa (2001), socióloga argentina de largo recorrido, se rescata la privatización de las urbanizaciones en Argentina como denominador común de los modelos de vivienda. Para la autora, los barrios cerrados simbolizan la expansión de una segregación espacial que ampara la separación de grupos y la homogeneidad residencial.

Tabla 1. Tipos de urbanizaciones y valores privilegiados

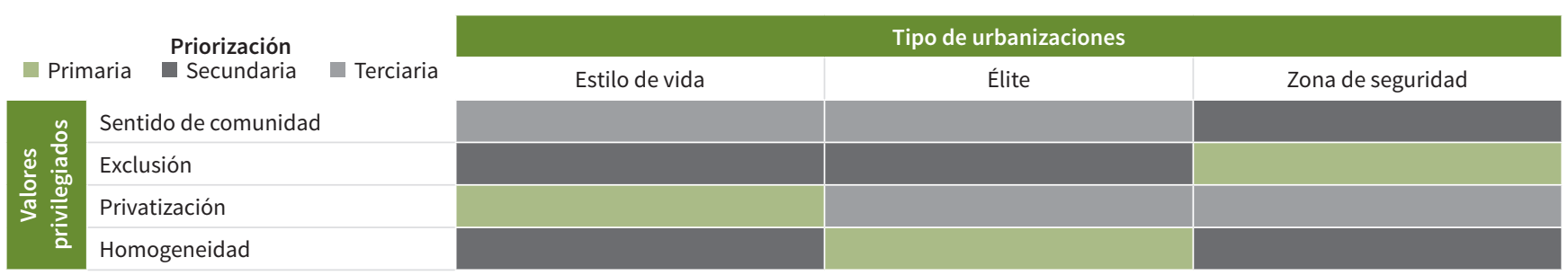

Fuente: traducción y adaptación del autor a partir de Blakely y Snyder (1997) 
En el libro Los que ganaron, presentado al público por primera vez en el 2001, Svampa (2001) analiza las dimensiones más relevantes de la segregación en los conjuntos cerrados de Argentina. En dicho documento la autora considera un manojo de riesgos que se potencian con el fenómeno privatizador de las urbanizaciones, rescatando tres elementos cruciales que ascienden como consecuencias para el englobe de la ciudad: el retiro del Estado, la promoción de una ciudadanía privada y la declinación del espacio público. Sin embargo, tomando como línea de partida los anteriores, Svampa (2001) devela que la formalización de un ciudadano unívocamente contribuyente es resultado principal de un modelo exclusivamente neoliberal. Como Snyder y Blakely (1997) sustentan, "las comunidades cerradas son zonas residenciales de acceso restringido en las que normalmente están privatizados los espacios públicos ${ }^{11}$ (p. 2); por ello, los servicios indispensables, como la vivienda, la educación, la seguridad y la reparación de vías, se encuentran separados de los roles públicos y del contacto heterogéneo que Jacobs (2011) patrocinó como principio indispensable.

Para Mike Davis (2003), las ciudades se encaminan a sistemas fortaleza que recalcan la edificación de muros, y el abandono de parques y plazas de circulación constante. Abandonar la ciudad supone patrocinar modelos segregativos como las agrupaciones de vivienda, y, como consecuencia, genera lo que Davis (2003) reconoce como el apartheid urbano, el nido perfecto para el aislamiento y la marginación espacial. Para el autor, la búsqueda de la seguridad, también asumida por Blakely y Snyder (1999), aglutina la causa principal de una cadena de productos que rotulan la ciudad en términos sociales y económicos. Por ejemplo, la reforma de los equipamientos y el desarrollo de una arquitectura orientada al camuflaje - manejo de fachadas - se vislumbran como consecuencias vertebrales de la privatización barrial, acompañadas de una huida de la calle y el deseo creciente de la semipublicidad. Junto a Davis (2003), Blakely y Snyder (1997) priorizan las problemáticas de la privatización, la exclusión social y la segmentación espacial como raíces y fruto de la agrupación residencial. Para ambos investigadores la función democrática de la ciudad y la pluralidad imperante dentro de ella debe prevalecer por encima de un conjunto de modelos que preponderan las cualidades físicas y monumentales en vez de las humanas e integradoras.

En el caso de Svampa (2001), quien no se aleja demasiado del discurso manejado por otros académicos, la excesiva reglamentación advierte la principal contrariedad de las urbanizaciones amuralladas, a tal punto que llega a afectar a paseantes y habitantes. Al igual que los demás, ella también reclama ante una privatización que estropea cada arteria de los centros y periferias de la ciudad, señalando lo siguiente en materia de transformaciones y alteridades en el espacio y en la vida: "el tratamiento de las nuevas relaciones entre lo público y lo privado no puede

\footnotetext{
1 Traducción del autor.
}

escamotear una realidad: el surgimiento de una ciudadanía privada que va desplazando a un modelo de ciudadanía política, apoyada en criterios universales y, por ende, más generales" (Svampa, 2001, p. 204).

Ahora bien, contrario a la postura de autores como Davis (2003) y Blakely y Snyder (1999), escenarios como la ciudad dentro de la ciudad han apostado por un espacio público mucho más humanizado. Lejos de aquellos parámetros de privatización y segregación espacial, este tipo de urbanización ha privilegiado el acceso libre, la circulación continua y la participación comunitaria. Para Germán Samper (1997), arquitecto promotor de este tipo de macroproyectos, la agrupación de vivienda se introduce como componente sustancial de la ciudad en el contexto de los años sesenta y asciende como solución primaria a la carencia continua de parcelas. La reducción de las áreas de loteo, la construcción en forma de serie, la configuración de espacios comunales y la divulgación de zonas verdes se amenizan como objetivos vertebrales de un esquema residencial que procura adaptarse a una lista de transformaciones que trastoca cada particularidad de los centros urbanos. A este punto las ciudadelas se producen como alternativa a los problemas de la ciudad -movilidad, acceso, desplazamiento-y se enmarcan como ambientes frondosos de tranquilidad y fluidez urbana. La ciudad dentro de la ciudad se concibe como amplitud residencial de equipamientos y actividades, que Samper (1997) bien definió como síntesis de divergencia: "hace referencia a la necesidad de descentralizar todos los servicios que requiere el ciudadano y evitar así desplazamientos masivos de personas en busca de servicios que se pueden prestar relativamente cerca de las viviendas" (p. 181).

Samper (1997) sustenta que la agrupación residencial avala por la integración continua con la red urbana y va en contra de la apropiación de los bienes públicos; por el contrario, busca la reorganización del espacio construido y el desarrollo de movilidades ampliamente amables. Así mismo, permite la construcción de supermanzanas, la creación de un concepto de áreas comunales, la libertad de diseño y la generación de socialización, todas ellas enmarcadas como principios indispensables de los modelos de vivienda. Para Samper (1997), las relaciones afianzadas dentro de los conjuntos no se alinean con los asuntos segregativos que proponen Davis (2003) y Blakely y Snyder (1999) en sus diferentes análisis; las ventajas de potenciar las agrupaciones de vivienda se encuadran en la favorable integración entre la propiedad pública, privada y comunal, y en vez de satisfacer únicamente los dineros particulares, se interesa por las relaciones amenas que se generan en su interior.

Samper (1997) recalca que las agrupaciones de vivienda son escenarios en los que prima la multiplicidad y la divergencia; "su gran cualidad es que permiten ambientes residenciales que rescatan la escala humana y en donde se puede desarrollar un concepto de solidaridad entre vecinos para el buen mantenimiento del entorno" (p.51). Además, menciona las grandes oportunidades que representa este tipo de proyectos para los arquitectos, ya que, aparte de proporcionar libertad de diseño, otorga 
la posibilidad de brindar lugares amables y relativamente seguros a los usuarios. El autor no duda en presentar la vía pública como elemento trascendental donde germina el acontecer de la ciudad, sin embargo, invita a mantener un equilibrio entre el espacio público y el privado a fin de favorecer las relaciones armónicas entre ambas esferas. En sus reflexiones presenta al recinto como adecuación propicia para la vida pública; en él acontecen las interacciones humanas y se incentiva el asentamiento de la heterogeneidad social, elemento que imprime la humanización de la ciudad.

Las urbanizaciones promotoras de libre circulación, en las cuales se permite el tránsito de actores externos sin ningún tipo de inconveniente, posibilitan el desarrollo de procesos de participación y comunicación mucho más profundos. Las decisiones tomadas en colectivo son pensadas en pro del disfrute de una comunidad interna y externa, donde no solo los residentes son tomados en cuenta, sino también los visitantes como actores decisivos. Así, lo público se enriquece de posiciones divergentes, de discusiones latentes sobre su aprovechamiento y condición, pero aún más importante, de situaciones que favorecen su mixtura y conflictividad. Escenarios como las urbanizaciones abiertas recrean espacios públicos de actividades alternas, cambiantes y adaptables a las necesidades de la comunidad; promueven la presencia de sujetos con sentires, pensamientos y realidades singulares que se vinculan con la vida de otros que son igual de diferentes. En la ciudad dentro de la ciudad la calle vuelve a cobrar protagonismo, se concibe como vértebra del trasegar cotidiano, que ahora es testigo de las relaciones sociales que se incentivan con la interacción.

Para Germán Samper (1997), la cualificación humana de las ciudades se afianza a partir de un tratamiento adecuado de los equipamientos y del apropiado ordenamiento de las vías. Humanizar la ciudad significa modificar el diseño de los barrios, categorizar la malla vial, construir grandes manzanas y establecer una intercomunicación entre el hombre y los sistemas de transporte, especialmente el automóvil. El tránsito humano es para Samper un elemento indispensable en la configuración de conjuntos residenciales promovidos como sistemas comunitarios; en ellos se debe procurar mantener las vinculaciones entre vecinos cercanos y recalcar el aspecto humanizante del espacio público. Inquietarse por la ciudad dentro de la ciudad, derivada de diferentes modelos de vivienda implementados con el paso de las décadas, representa una búsqueda por comprender las divergencias presentes en sus entornos, que a pesar de ser ampliamente criticados en los últimos años, pocas veces se han considerado según sus movilidades internas y a través de un escenario que logra develar la permanente calidad de la condición humana: la espacialidad pública.

\section{Consideraciones finales}

El espacio público, enmarcado en el contexto de las urbanizaciones, ha potenciado reflexiones académicas que dan como resultado posiciones analíticas ampliamente diferentes. Para algunos investigadores interesados en la temática, la construcción de complejos residenciales en la ciudad ha permitido que los espacios públicos se privaticen, al punto de que las oportunidades para disfrutar y compartir se ven restringidas con el paso de los años. Sin embargo, una postura opuesta a la anterior devela que nuevos modelos de vivienda como la ciudad dentro de la ciudad, la cual procura la comunicación urbana y el desarrollo eficiente de equipamientos, avalan por espacios públicos de cualidades participativas y por entornos que permitan el tránsito sin ningún tipo de restricción.

A pesar de las detracciones realizadas por Blakely y Snyder (1997), además de Svampa (2001) y demás teóricos que han reflexionado sobre los espacios públicos, es apremiante rescatar las nuevas estrategias urbanísticas interesadas en la humanización del espacio, que buscan privilegiar al hombre por encima de la distribución de inmuebles. Considerando los aportes realizados por Brandão (2011) al análisis del espacio público, es preciso evidenciar que los escenarios públicos presentes en urbanizaciones o conjuntos residenciales deben potenciar la apropiación e incentivar su protección por parte de residentes y visitantes. La formalización de topónimos por consenso social al interior de estos lugares posibilita que las relaciones y las actividades se encuentren vinculadas con el espacio, que los trasegares cotidianos se basen en significados reconocidos por toda la comunidad y que las aprehensiones sean profundas al punto de incentivar el ejercicio de preservación. La construcción de nominaciones colectivas, relevantes y no impuestas por terceros, hace posible que el sentir de las personas se priorice, reflejando con ello la concreción de espacios públicos eficientes, adecuados y amenos para la población destinataria.

Igualmente, es desafío de constructoras y urbanizadoras estimular la presencia de distintos usuarios en el espacio; la heterogeneidad permite el crecimiento de oportunidades concretas de disfrute $y$, además, posibilita desarrollar relaciones conflictivas que son indispensables al momento de pensar sobre lo público. La actividad cotidiana de peatones, familias, comerciantes y colectivos es parte de un entramado cargado de subjetividades diversas, de una visión profunda que carga de sentido a la mayoría de los espacios públicos. La presencia del extraño y el encuentro con lo desconocido es fundamental para que los equipamientos planeados al interior de los complejos de vivienda recojan la amplitud de gustos y necesidades colectivas; es trascendental pensar en espacios públicos atiborrados de divergencia para con ello impedir privatizaciones basadas en individualidades y egoísmos.

Ahora bien, incentivar el desarrollo de proyectos como las ciudades dentro de la ciudad, aparte de ser necesario para la correcta organización 
de las zonas urbanas, supone privilegiar la calle como escenario para la participación y el intercambio humano. Sobrepasar las concepciones tradicionales de las vías como puntos de tránsito diario sin niveles de importancia es un reto para un modelo de vivienda que se preocupa por hacer de la calle un lugar de exploración. Igualmente, la promoción de actividades gestionadas por residentes, junto con la creación de monumentos significativos para las comunidades, requiere de constantes esfuerzos encaminados a la formalización de espacios públicos cálidos y amenos para el usuario. Apostar por escenarios públicos cooperativos, heterogéneos y basados en el encuentro ha sido la estrategia de proyectos como la ciudad dentro de la ciudad, que ha logrado promover un modelo organizado de vivienda y un sentido de lo público que rebasa las barreras de las urbanizaciones cerradas tan conocidas hoy a lo largo del mundo.

\section{Referencias}

Arendt, H. (2003). La condición humana. Buenos Aires: Paidós.

Blakely, E. y Snyder, M. (1997). Divided we fall: gated and walled communities in the United States. En N. Ellin (ed.), Architecture of fear (pp. 85-100). Nueva York: Princeton Architectural Press.

Blakely, E. y Snyder, M. (1999). Fortress America. Gated communities in the United States. Washington: The Brookings Institution.

Borja, J. (2003a). El espacio público, ciudad y ciudadanía. Barcelona: Electa.

Borja, J. (2003b). La ciudad conquistada. Madrid: Alianza

Brandão, P. (2011). La imagen de la ciudad: estrategias de identidad y comunicación. Barcelona: Edicions Universitat Barcelona.

Davis, M. (2003). Ciudad de cuarzo. Arqueología del futuro de Los Ángeles. Madrid: Lengua de Trapo.

Delgado, M. (1999). El animal público. Barcelona: Anagrama.

Delgado, M. (2011). El espacio público como ideología. Madrid: Catarata.

Jacobs, J. (2011). Muerte y vida de las grandes ciudades. Madrid: Capitán Swing.

Joseph, I. (1999). Retomar la ciudad: el espacio público como lugar de la acción. Medellín: Universidad Nacional de Colombia.

Habermas, J. (1981). Historia y crítica de la opinión pública. Barcelona: Gustavo Gili.

Habermas, J. (1989). Jürgen Habermas on society and politics: a reader. Boston: Beacon Press.

Samper, G. (1997). Recinto urbano: la humanización de la ciudad. Bogotá: Escala.

Sennett, R. (1978). El declive del hombre público. Barcelona: Península.

Svampa, M. (2001). Los que ganaron: la vida en los countries y barrios privados. Buenos Aires: Biblos. 